\title{
UNA NOTA SOCIO-HISTÓRICA A LOS CAPÍTULOS 36 Y 50 DE LA SEGUNDA PARTE DEL QUIJOTE
}

\author{
"Entonces no se usaban coches ni \\ sillas, como agora dicen que se usan" \\ (Doña Rodríguez en Quijote, II, 48).
}

Como pone de manifiesto la repulgada Doña Rodríguez, los textos literarios de más de dos generaciones de autores del Siglo de Oro menudean de alusiones a un debate contemporáneo, el de los coches de caballo. Autores de muy diferente filiación social y artística coinciden en criticar o condenar el uso de carruajes en el medio urbano. El mismo motivo surge en Lope y se reproduce sin pausas hasta Calderón y Quevedo y, aún más allá, hasta Azcona en el costumbrismo. La novela cortesana colma la medida en la repetición del molde y de la letra de la condena de los vehículos suntuarios. Todas las voces autorizadas, incluidas las de los reyes en sus premáticas, y algunas de las voces menores insisten en atacar la afición desmedida de la sociedad de todo un siglo por andar en coche o, en la formulación al uso, ruar ${ }^{1}$. Cervantes adopta el tópico y sus formas más vulgares en su Entremés del vizcaíno fingido, en su Licenciado Vidriera ${ }^{2}$ y en los capítulos 36 y 50 de la Segunda Parte de El ingenioso hidalgo, aunque en este caso, como veremos, se trata de una contrahechura o de una transformación creativa.

Con todo, la crítica moderna, en su acostumbrado soslayamien-

1 Vid., por ejemplo, el «Entremés famoso de los coches» de LUIS QUiÑonES DE Benavente, incluido en Entremeses, Christian Andrés, ed. Madrid, Cátedra, 1991, pp. 68-78. Otros muchos textos alusivos han sido anotados por IgNACIO ARELLANo y ÁNGel R. FERnÁNDEZ en su edición de El diablo cojuelo. Madrid, Castalia, 1988, p. $61 \mathrm{n}$.

2 Remitimos al lector a la edición clásica de las Novelas ejemplares de FrancisCo RODRíGUEz MARín con la nota más erudita sobre nuestra cuestión (Madrid, Espasa, 1943, vol. II, pp. 50-52). 
to de lo social aplicado al análisis literario, ha confinado el asunto a los trabajos críticos con vocación enciclopédica y a las notas al pie a los lugares de aquellas obras del XVII en los que se hace sentir la queja contra los carruajes, tales como los dos pasajes del Quijote de los que aquí nos ocupamos. Así, Diego Clemencín comentó y acumuló citas en la nota de su edición de la novela ${ }^{3}$ y Francisco Rodríguez Marín, padre de la «microcrítica», incluyó un apéndice amplio sobre el asunto en la suya, junto con una nota muy completa en la de las Novelas ejemplares ${ }^{4}$. Ricardo del Arco y Garay, en el mismo tono y con menos lujo de fuentes, comentó los lugares cervantinos en los que se registra el debate en su obra filocostumbrista La sociedad española en las obras de Cervantes ${ }^{5}$.

Modernamente contamos con dos tratamientos más analíticos en el plano de lo social literario: José Antonio Maravall ha investigado el motivo de los coches en las obras picarescas ${ }^{6}$ y José M. Díez Borque ha incluido el asunto en su Sociología ${ }^{7}$ citando uno de los textos en los que centraremos nuestro análisis. La atención dedicada al tema se limita, por lo demás, a esas notas acumuladas sobre un puñado de alusiones al tópico en las obras áureas más reeditadas. En estos casos se tiende a referir al lector a las premáticas reales y a otras obras con pasajes del mismo tenor. Así, Luisa López Grijera ha anotado La hora de todos de Quevedo ${ }^{8}$ y la norma ridícula de los don Toribios del Buscón de andar en coche prestado una vez al mes viene siendo objeto de comentarios al pie desde don Américo Castro ${ }^{9}$. El famoso pasaje de los «encochados» del Tranco II del Diablo Cojuelo de Luis Vélez de Guevara, diferente en técnica y recurso de los que nos traen a estas páginas, ofrece el mismo tema cocheril y Enrique Rodríguez Cepeda ${ }^{10}$, Ángel R. Fernández e Ignacio Arellano ${ }^{11}$ han aportado independientemente sus comentarios.

3 El ingenioso hidalgo don Quijote de la Mancha. Madrid, 1894, vol. VI, pp. 369-373.

4 Desdoblada en dos: Madrid. La lectura, 1922, y la más extensa de Madrid, Atlas, 1949, con un apéndice sobre el asunto en vol. X, pp. 102-111. Vid., asimismo, los comentarios al mismo pasaje en la edición del Quijote de CLEMENTE CORTEJÓN. Madrid, Victoriano Suárez, 1913.

5 Madrid, Patronato del IV Centenario del Nacimiento de Cervantes, 1951, pp. 386-389.

6 José Antonio Maravall, La picaresca desde la historia social. Madrid, Taurus, 1986, pp. 583-590.

7 Sociología de la comedia española del siglo XVI. Madrid, Cátedra, p. 269.

8 Madrid, Castalia, 1975, p. 88n.

9 Madrid, Espasa, 1973, 151n. Vid. también el mismo pasaje en la edición más reciente de Domingo Yndurain, Madrid, Cátedra, 1985, y en la de Fernando Cabo Aseguinolaza. Barcelona, Crítica, 1993.

${ }_{10}$ Madrid, Cátedra, 1984, en notas de las pp. 69 y 84.

11 Ed. cit., loc. cit. 
Como en el chiste mencionado de Vélez, los muchos lugares de Quevedo sobre el motivo difieren de los quijotescos que nos ocupan en el particular distanciamiento de lo real operado por la sátira barroca, elevada en aquéllos a su máxima expresión. Por último, el entremés cervantino de El vizcaíno fingido ha sido puntualmente anotado, en lo que nos concierne, por Eugenio Asensio ${ }^{12}$ y por Juan Alcina Franch ${ }^{13}$. Y José de Cavalari Pazos extractó la famosa premática de los coches y las mujeres de mala vida en el «Rasguño de análisis» o prólogo de su añeja edición gaditana del citado entremés ${ }^{14}$. Tales son, en fin, algunos de los antecedentes críticos con que cuenta el anotador del Quijote para este particular asunto.

Ya instalados don Quijote y Sancho en uno de los pasajes más celebrados de la segunda parte de la novela, el episodio carnavalesco de la Ínsula Barataria, Sancho y Teresa se intercambian cartas con las buenas nuevas de la corte insular y de la aldea manchega ${ }^{15}$. La quimera barataria ha renovado en el escudero sentimientos confusos de ascenso social que nacieran en su primera entrevista con su amo en I, 7 y que se manifestarán a raudales en la carta a su Oíslo, la a ratos Mari-Gutiérrez, a ratos Juana Gutiérrez y a ratos Teresa Panza.

Deslavazada como Sancho mismo y como sus refranes y cuentos, la carta del capítulo 36 transmite a la esposa un apremiante ruego de su marido: «Has de saber, Teresa, que tengo determinado que andes en coche, que es lo que hace al caso, porque todo otro andar es andar a gatas" ${ }^{16}$.

El gobernador que esto escribe es el mismo que conserva su rucio rodado en los establos del palacio y que abandona su gobierno tras pronunciar un discursito a lo Guevara (II, 53). Aduce Sancho dos razones para que Teresa ande en coche. La primera es del todo barataria, esto es, ejecutiva y oscura: «es lo que hace al caso». $\mathrm{Y}$ puede ser interpretada bien como una consabida coletilla protocolaria (el caso es la costumbre suntuaria de los gobernadores recientes), bien como una más compleja y lacónica ordenanza social

12 Entremeses. Madrid, Castalia, 1970, p. 151n.

13 Entremeses. Barcelona, Juventud, 1968, p. 201n.

14 Ocho entremeses de Miguel de Cervantes Saavedra. Cádiz, 1816.

15 Las fuentes de las cartas y de los consejos de don Quijote a Sancho han sido resumidas por FrANCISCO MÁRoUez VILlanueVA, Fuentes literarias cervantinas. Madrid, Gredos, 1973, p. 237. La filiación de Guevara no ofrece mucho lugar a dudas, pero no abarca, que sepamos, el asunto de los coches, más probablemente inspirado en la plétora de textos contemporáneos con alusiones cocheriles y en la propia realidad histórica.

16 Citamos el texto de la edición de Martín de Riquer. Barcelona, Juventud, 1958, II, p. 36. 
en la que el caso es un caso de promoción social y lo que hace es la expresión de una nueva necesidad instrumental que importa al protagonista de tal promoción. Sea como fuere, la segunda razón es más sanchesca: "porque todo otro andar es andar a gatas». La duda se aclara. Lo que realmente le importa a Sancho es la estima social debida a los familiares de los funcionarios de su escalafón.

Ya de muchos capítulos antes sabemos que el vehículo hace a su conductor. Don Quijote tuvo sus dudas antes de permitir a Sancho andar "caballero asnalmente», pues los escuderos andantes, como se sabe, llevan esa "más honrada caballería» que el futuro Caballero de la Triste Figura dispone para el suyo (I, 7). Parecida prerrogativa corresponde, según el caballero, al cura en I, 29.

De otros caracteres con los que nuestros protagonistas se topan en caminos, encrucijadas y ventas no sabemos, ni saben ellos, nada más que lo que las cabalgaduras, los carros, los vestidos o el porte indican. En un mundo mercantil y activo, con la península cruzada por arrieros, pretendientes, soldados, mercaderes y funcionarios como el propio Cervantes, entre otros muchos, no es fácil atribuir a cada uno su estado sin recurrir a los aperos y a las apariencias: los ricos llevan coches, como la "princesa» de I, 8 o buenas mulas, como Cardenio y como el protagonista de La Gitanilla; los pobres van a pie, como Andresillo o Ricote, como Rincón y Cortado. Las mulas varían de tamaño y andares en función de su precio. La experiencia personal del Cervantes alcabalero y andariego, a la par que su verismo, le llevan a describir casi profesionalmente, como un tratante, las mulas de todos los que así andan por sus obras, según muestra muy bien el artículo de Moisés García de la Torre ${ }^{17}$. Por citar dos ejemplos, en II, 10 se debate si los que montan las tres aldeanas son pollinos o pollinas; en el inefable episodio del yelmo de Mambrino amo y escudero tienen sus más y sus menos sobre la asnez o la caballez del rucio del barbero y Sancho concluye con una especie de baciyelmo sintáctico: "caballo rucio rodado, que parece asno pardo» (I, 21). Las bromas del Cervantes conocedor de las caballerías llegan a su colmo cuando compara a Clavileño con las mulas de retorno (II, 40) ${ }^{18}$.

17 "Cervantes y el mundo de los caminos: las mulas. Realidad histórica y ficción literaria», en MANUEl CRIADO DE VAL, ed., Cervantes, su obra y su mundo. Actas del I Congreso Internacional sobre Cervantes. Madrid, EDI-6, 1981, pp. 213-225. Vid. especialmente pp. 220-225.

18 En el prólogo del Persiles los personajes y Cervantes tratan de los diferentes andares de sus caballerías. Aunque tales disquisiciones no son infrecuentes entre otros autores del Siglo de Oro español, sí adquieren especial pormenor en las obras del alcalaíno. Asimismo, Vicente Espinel anota los resabios de la mula de Marcos en su viaje malagueño del Descanso VIII de la primera parte de la Vida de Marcos 
El pasaje epistolar citado se completa con una discusión amena de madre e hija Panza, del paje, el cura y el bachiller en casa de Teresa y con motivo de nuestra carta. Los Panza y el enviado de la duquesa debaten la cuestión candente de las caballerías de los familiares de gobernadores, precisamente movidos por la frase sanchesca que nos ocupa. Madre e hija se congratulan por la nueva ventura e imaginan sus paseos en carroza. Exclama Sanchica:

\begin{abstract}
Pluguiese a Dios que fuese antes hoy que mañana, aunque dijesen los que me viesen ir sentada con mi señora madre en aquel coche: «iMirad la tal por cual, hija del harto de ajos, y cómo va sentada y tendida en el coche como si fuera una papesa!». Pero pisen ellos los lodos, y ándeme yo en mi coche, levantados los pies del suelo (II, 50).
\end{abstract}

Una descripción de la muchacha que trae precisamente el recuerdo del pasaje mencionado de El vizcaíno fingido, en el que Brígida lamenta la oportunidad perdida de pasear en coche las mujeres de su condición, tras la famosa premática suntuaria que veda tales paseos:

$¡$ ¡y, Cristina! no me digas eso, que linda cosa era ir sentada en la popa de un coche, llenándola de parte a parte, dando rostro a quien y como y cuando quería. Y, en Dios y en mi ánima te digo, que cuando alguna vez me le prestaban, y me vía sentada en él con aquella autoridad, que me desvanecía tanto, que creía bien y verdaderamente que era mujer principal, y que más de cuatro señoras de título pudieran ser mis criadas ${ }^{19}$.

Teresa, confirmando nuestros supuestos, retiene la frase cocheril de Sancho con una fijación especial que la hace repetirla en dos ocasiones en su respuesta a la duquesa. La primera vez, la carroza aparece nada menos que como la meta de su viaje a la corte barataria: «Yo, señora de mi alma, estoy determinada, con licencia de vuesa merced, de meter este buen día en mi casa, yéndome a la Corte a tenderme en un coche...» (II, 52). Pocas líneas más adelante, Teresa se ve a sí misma en tal papel:

... Que me dicen mis amigas y mis vecinas que si yo y mi hija andamos orondas y pomposas en la Corte, vendrá a ser conocido mi marido por mí más que yo por él, siendo forzoso que pregunten muchos: "¿Quién son estas señoras deste coche?». Y un criado mío responderá: «La mujer y la hija de Sancho Panza, gobernador...».

de Obregón, edición de Samuel Gili Gaya. Madrid, Espasa, 1969, vol. I, p. 120. A Quevedo no lo guía intención realista alguna, sino el afán de explotar todas las posibilidades satíricas de la caída del «rey de gallos» en su Buscón, edición mencionada de Domingo Yndurain, pp. 109-111. Su insistencia en la flaqueza del rocín es idéntica a su reforzamiento del valor de lección social que tal caída posee.

19 Entremeses, edición citada de Eugenio Asensio, p. 152. 
Así las cosas, las claves sociales son, si cabe, aún más reconocibles en las palabras de la mujer. Si Sancho ocultaba los móviles de su disposición cocheril, su mujer se basta para aclarar el entuerto: el coche honra a la esposa del gobernador campesino y la honra así adquirida por aquélla repercute socialmente en la condición de éste. Lo que más hace al caso no es, sin embargo, el proceso de rebotes honoríficos que lleva a Teresa a creer que su marido se honrará por los andares y los rodares de su esposa y su hija, sino el hecho de que el instrumento de esa honra mostrenca sea una carroza con su acompañamiento de criados a la vista de los cortesanos curiosos ${ }^{20}$.

Lo que se esconde tras la obsesión cocheril de los esposos Panza es el conflicto contemporáneo entre, al menos, dos concepciones del ser noble: la de los nobles de estirpe, en parte contaminados por sus matrimonios de interés con las casas enriquecidas, pero de sangre oscura o dudosa y, de otro lado, la nobleza o hidalguía vieja, pero pobre, tan antigua y tan sin mezcla como se quiera y tan empobrecida como se lee en el Buscón, en el Lazarillo y en tantas otras obras. A la vez, según ha dicho Maravall a propósito del teatro de Lope de Vega ${ }^{21}$, hay una casta de campesinos ricos sin tachas en su sangre, pero sin nombre de nobles, que blasona de su antigüedad castiza y de sus riquezas. Sancho y los suyos, sin ser otra cosa que simples labriegos, pretenden nadar entre estas dos aguas, la corriente de los propietarios rurales sin alcurnia, pero con muchos ducados (esos dineros que Sancho se afana en sacarle a su ínsula, a las maletillas de las mulas abandonadas, a los baciyelmos, a su gobierno insular...) y la nueva nobleza mezclada o comprada de los funcionarios instalados en las cortes, situación del propio gobernador Panza. De ahí que le recalque a su mujer que «por una vía o por otra, tú has de ser rica, de buena ventura» (II, 36).

Estos personajes liminares están, como el escudero, interesados en ostentar la autoridad que brinda el coche a sus usuarios. Los duques de nuestra historia, que crean la ficción barataria, e indirectamente la ilusión cocheril en los Panza, se hallan próximos a

20 En todo esto hay algo más que el puro disparate cervantino que se escondía, por ejemplo, en aquella otra idea de Teresa de hacer a Sancho alcabalero. Prueba de ello es que, si el cariz autobiográfico de tal broma queda iluminado con la lectura de cualquiera de las biografías cervantinas, en cambio, la base a medias real del discurso cocheril de Teresa y Sancho no pide más prueba de su verismo que el peso considerable de los testimonios contra los coches de tantas obras áureas. En todo caso, aún a pesar de que este rasgo "realista" puede ser fehacientemente confirmado en lo histórico, no es de este lugar el dar completa razón de semejante paralelismo, demasiado explotado ya por la crítica literaria decimonónica.

21 En su Teatro y literatura en la sociedad barroca. Madrid, Seminarios y ediciones, 1972, cap. VIII. 
este último grupo, pues, como se sabe, la nobleza oriental se hallaba muy emparentada con esas castas proscritas a las que pertenecieron ascendientes del propio rey Fernando el Católico. Cervantes hace decir al paje ducal, quizá sin malicia (aunque esto es harto difícil de creer), que «las señoras de Aragón, aunque son tan principales, no son tan puntuosas y levantadas como las señoras castellanas» (II, 50). No hay que pensar que Sancho sea, sin embargo, completamente consciente de todo el asunto de los casticismos, aunque pueda ser a ratos castizo en el sentido de Don Américo.

El episodio de la ínsula confunde a Sancho, pero también le proporciona una nueva clarividencia social. Obran en él, desde el comienzo de su participación en la novela, dos impulsos antagónicos y complementarios ${ }^{22}$ : su llaneza casi impermeable a todo refinamiento y su deseo de hacerse rico. Con la primera riqueza que le depara la fortuna -en su vocabulario, "ventura», en el de Teresa también «buen día»- paladea el sabor de lo que él cree ha de sobrevenirle legítimamente. Son los doblones que calla y no le devuelve a Cardenio. El segundo golpe de ventura es la tan esperada ínsula. En ésta no ve dinero alguno, pero adquiere conciencia de la identidad social de la riqueza y la nobleza. Sancho y su amo habían dado ya antes, sin embargo, suficientes barruntos de estas ideas en las frases corrosivas de I, 21.

Esa ventura que invocan las Panza como el móvil de su súbito encumbramiento social es un impulso nuevo en la realidad del Siglo de Oro. Su fuerza se opone exactamente a la de la inercia de la sangre. La ventura es el bien inesperado: la maletilla de dineros hallada en Sierra Morena, la ínsula o, para Teresa, los corales de la duquesa. Puede adoptar, asimismo, el aspecto tentador y fraudulento del tesoro morisco de Ricote. Lo novedoso del caso es que esta ventura no es equiparable a la fortuna medieval más que en sus aspectos externos. La nueva fuerza actúa en el plano vertical de la sociedad, hace a los pobres ricos y - he aquí la variacióntambién nobles cuando la opinión, la limpieza de sangre y otros factores retardatarios así lo permiten. En tanto que la antigua for-

22 No en vano ha sido descrito como un personaje cambiante, entre otros, por EDMUND DE CHASCA («Sancho Sanchuelo, sancho-sancho, sancho-sanchísimo» en JoSEP M. Solà SolÉ et al., Estudios de hispanistas norteamericanos dedicados a Helmut Hatzfeld. Barcelona, Hispam, 1974, pp. 73-86), DÁMASO Alonso («SanchoQuijote, Sancho-Sancho", Del Siglo de Oro a este siglo de siglas. Madrid, Gredos, 1962, pp. 9-19) y, antes, WILLIAM S. HENDRIX («Sancho Panza and the Comic Types of the Sixteenth Century», en Homenaje ofrecido a Menéndez Pidal. Madrid, 1925, II, pp. 485-494) y AMÉRICO CASTRO (Cervantes y los casticismos españoles. Madrid, Alfaguara, 1974, p. 90). Para una síntesis, vid. Francisco MárQuez Villanueva (Fuentes literarias cervantinas. Madrid, Gredos, 1973, p. 84). 
tuna, todavía en vigor para los caballeros como principio teórico, decidía tiranamente el porvenir de todos sin permitirles pasar de un estado a otro. Mataba a las personas o hundía los patrimonios, pero no era capaz, en principio, de honrar a nadie más allá del estado concedido por nacimiento. Las excepciones confirmaban la regla y en el mismo Don Quijote ya se difuminan sospechosamente los contornos de ambas fuerzas.

La ventura es, pues, una especie de honra o de hacienda mostrenca que sobreviene a algunos afortunados. Claro está que el que debe su suerte social a tal impulso favorable no las tiene todas consigo. Otros detentan una posición en la sociedad que les han concedido el tiempo, las hazañas propias o las de algún antepasado, según parece suceder a las altaneras hidalgas de la aldea de Don Quijote y Sancho, parientes de los aldeanos ricos de Lope. La ventura no posee, sin embargo, la respetabilidad de lo establecido, y el venturoso se halla, más que nadie, a expensas de los murmuradores, como muy bien sabe la Sanchica de II, 50: «iMal año y mal mes para cuantos murmuradores hay en el mundo...!». Esa murmuración procede, en parte, de la crítica de los nobles antiguos hacia los hombres nuevos. Sancho, con todo, no puede estar peor que otros, pues es "hombre de bien» (I, 7) y cristiano viejo, aunque no entre en iglesia alguna.

Tal es la clave que ilumina el asunto de los coches. La ventura se materializa en objetos suntuarios, en posesiones temporales que cualquiera puede instrumentalizar en su beneficio. Suele ser codificada por medio de objetos portátiles, de adornos, de vestidos o armas y, en menor medida, a través de casas o tierras, es decir, todo lo que brinda esa «autoridad» en la que insisten Sanchica, Brígida e incluso la mentada Doña Rodríguez en II, 48, cuando se refiere a aquella ama suya que poseía una "poderosa mula, negra como el mismo azabache». Siendo así, qué mejor portavoz de la ventura de un usurpador que un vehículo o una caballería de cierto fuste, como el inexistente caballo "porcelana" de Pablos ${ }^{23}$. En una sociedad preocupada hasta el extremo por las apariencias, importa ante todo que las apariencias sean ligeras y llevaderas, para así contar con un público más amplio. J. A. Maravall ${ }^{24}$ ha subrayado la naturaleza instrumental de los coches como pregoneros de la posición social y la autoridad de sus dueños o, como bien saben tantos caracteres de comedia y tantos pícaros, de sus usuarios por préstamo o alquiler.

23 El Buscón, edición citada, p. 258. O aquel otro que, con idéntico fin, toma prestado en Madrid (p. 267).

${ }^{24}$ La picaresca desde la historia social, pp. 583-590. 
El consumismo y la industria del lujo invitaban a los adinerados a ostentar signos de posición social en público como han mostrado los escritos de Werner Sombart. A la postre, una misma intención de ostentar nobleza y disimular tachas guía a los hidalgos de Quevedo y del Lazarillo a ocultar su hambre con un mondadientes y a Mari Gutiérrez a moverse en carroza. La honra de sangre y de ideas que predicaban las obras de Lope era sólo a medias creída por los que la dictaban y la hacían cumplir. Lo característico del momento histórico es, como sostiene Maravall en el capítulo II de su Utopía ${ }^{25}$, el encuentro de dos sistemas. El repetidísimo «una onza de buena fama vale más que una libra de perlas» es casi un anacronismo en un tiempo que principia a ver la honra como otro valor de cambio, aunque sea el de precio más crecido y, quizás, más difícil de establecer. No en vano la abuela de Sancho Panza ya decía aquello de «tanto vales cuanto tienes» que su nieto ensarta refraneramente en II, 43.

La disolución del orden jerárquico medieval alcanza a nobles y plebeyos por igual. En el mundo al revés de la Ínsula Barataria los duques piden cargas de bellotas gordas y los gobernadores iletrados solucionan enigmas y dictan sentencias dignas de Catón «zonzorino». La realidad se transmuta sólo aparentemente, como en una hora de todos y aunque la apariencia sea la de una inversión de los valores admitidos, como en todas las sátiras, la verdad residirá en la exageración. El hecho es que las pocas letras del nuevo gobernador no son más que las poquísimas de los nuevos funcionarios tras las depuraciones debidas al orden castizo y las todavía menos de los nobles satirizados por Quevedo. Ya hemos apuntado la malévola alusión que parece encerrar la llaneza de los nobles aragoneses. Parejo valor, entre bromas y veras, se puede adscribir a ese encumbramiento repentino de los Panza. La farsa es real, la realidad farsa y los rústicos gobernadores: el mundo al revés y todos en su sitio. La duquesa parece adquirir a la sombra de Sancho el vicio de ensartar refranes y éste recobra aquel hablar «de tan rodeada manera» que Cervantes y Teresa le habían afeado en II, 5, y que constituye el preludio natural del prodigioso ennoblecimiento del futuro gobernador.

Tras la broma ducal se esconde, en efecto, la broma cervantina. Sancho es un cristiano viejo que apenas sabe firmar, a lo noble de Quevedo, con «unas letras como de marca de fardo» (II, 43). Resulta ser, llegado el momento, sin embargo, un pastor gobernador de lo más ilustrado y efectivo. Su concepción del poder es, con mucho, bastante más sana que la de los propios duques. Éstos son

25 Utopía y contrautopía en el Quijote. Santiago de Compostela, Pico Sacro, 1976. 
el verdadero reverso del buen gobierno de Sancho, pues revelan una habilidad teatral y una maldad opuesta a toda política virtuosa. Siendo así, ¿por qué no consentir moral y socialmente ciertos disimulos cocheriles a tan buenos cortesanos como los Panza? Sancho da mejor cuenta de la moral estoica de Cervantes que esos duques tan poco nobles. La cuestión no reside en el Quijote, como en otras obras, en autorizar o no el uso de carroza a los plebeyos ricos o a los nuevos funcionarios - Sancho es trasunto de ambas cosas-, sino en mostrar que, cuando los nobles antiguos abdican moralmente en labriegos expertos en el buen gobierno, tanto los unos como los otros merecen intercambiarse momentáneamente sus respectivas suertes sociales o, cuando menos, éstos se hacen acreedores de ciertas prerrogativas de los aristócratas, como la tan pregonada de andar en coche, que pueden ser igualmente detentadas por los plebeyos ${ }^{26}$.

Lo propio del momento social es, así pues, la coexistencia entre varios sistemas. Uno que cree en la honra innata (el «soy quien soy» del teatro de Lope que, como sabemos, conoce excepciones); otro que asocia la honra a la virtud, esquema estoico predicado por hombres como Cervantes y Enríquez Gómez y revelado distintamente en el episodio baratario; $y$, por último, un tercer sistema que hace a la honra un valor de cambio a la baja, un objeto suntuario como tantos otros. Las gentes como Sancho malentienden el estoicismo y lo interpretan en ocasiones como una expresión del tercer sistema, el monetario. Así, a las veces, el escudero retiene de los discursos de Don Quijote lo que menos hace al caso. Confundido entre los sermones estoico-caballerescos de su amo y una realidad dominada por el sistema monetario, alterna entre la codicia o el afán de poder y una versión a lo llano del Menosprecio de Corte de Guevara. Cuando gobernador, gobierna con justicia, pero su leit motiv de hacer dineros a todo trance lo traiciona en alguna ocasión, tal y como le hace saber la duquesa tras leer su carta a Teresa (II, 36). En otras palabras: su buena inclinación de «hombre de bien" tropieza con su deseo de instalarse en una sociedad cuyos mecanismos apenas empieza a comprender. Lo notable del caso es que, con todo, Sancho es mejor político que otros de sangre más esclarecida y aprende el estoicismo durante ese gobierno que tanto hace reír y tanto rebaja a los duques ${ }^{27}$.

26 Cf. Augustin REDONDo, "La tradición carnavalesca en el Quijote», en JAVIER Huerta CAlvo, ed., Formas carnavalescas en el arte y la literatura. Barcelona, Ediciones del Serbal, 1989, pp. 164-165, para una visión de la sátira política que encierra el episodio ducal y baratario.

27 Cf. REDONDO, art. cit., p. 167. 
La misma delicadeza (que es "ambigüedad" según Durán ${ }^{28}$ ) demostrada por Cervantes al instalar a Sancho en el engranaje social define el tratamiento del asunto cocheril por el autor del Quijote. Mejor dicho: el tema de los coches sirve como viñeta social más que como emblema moral. El modo en que esto se desenvuelve marca la distancia abismal entre la maniera ${ }^{29}$ polifónica y elusiva de Cervantes y el tono de condena sumarísima, emblemática, empleado por tantos otros para referirse a la moda de las carrozas. Cervantes elude el moralismo militante y se limita a montar un finísimo tejido satírico-social-moral sobre el bastidor de su novela ${ }^{30}$.

Por caminos muy distintos, Salas Barbadillo, Santos, Lope o Calderón alternan entre la filípica y la hipérbole monstruosa. Brochero elige el ataque legalista. Surgen los juegos más o menos fáciles: la broma de los encochados de Vélez y de Calderón, que éste último perfecciona satíricamente al enterrar a una dama en una carroza en El pintor de su deshonra ${ }^{31}$, las paronomasias de Quevedo (coche y coche de la sífilis; coche y cochino, coche y coche acá - una llamada para el ganado porcino según Autoridades-, su invención de un San coche, sus escenas de cocheros en las cuevas del infierno de Los sueños ${ }^{32}$ o su inolvidable asociación de la carroza prestada y la falsa hidalguía de Don Toribio. Se inventa la palabra COCHIZAR, el terminacho COCHEARSE de Tirso y el ECHAR COCHE junto al más inocente y afrancesado RUAR o al más local cursar el Prado. La carroza se hace igual a la dueña y al alcahuete en su misión de atolladero de honras. Castillo Solórzano, como las premáticas, reprende la alianza del coche y del tapado ${ }^{33}$. Todo ello respondía inicialmente a la realidad atestiguada con tintes tremendistas por Deleito y Piñuela, por Pinheiro da Veiga y por el refranero. Las manifestaciones del tópico son incontables; el tono es, sin embargo, común a todas ellas.

28 MANUEL DURÁN, La ambigüedad en el Quijote. Xalapa, Universidad Veracruzana, 1960.

29 Dicho sea este término sin ánimo de disputar sobre el barroquismo o el renacentismo del novelista.

${ }_{30}$ No hace falta decir que no postulamos la idea de la crítica positivista de un Quijote realista, rechazada modernamente por Menéndez Pidal y por Márquez Villanueva (op. cit., pp. 20-21), entre otros muchos. Las tesis biografistas de Agustín González de Amezúa, Francisco Rodríguez Marín y otros cervantistas ilustres transmiten la noción anacrónica de un Quijote inspirado directamente en hechos y personas reales e identificables.

31 Jornada I, esc. 3, pp. 870-871, de la edición de Obras completas de ÁNGEL VALBUENA BRIONES. Madrid, Aguilar, 1987.

32 Edición de Ignacio Arellano. Madrid, Cátedra, 1991, pp. 187-190.

33 Alonso de CASTIllo Solórzano, Lisardo enamorado, edición de EduARdo JULiÁ MARTíneZ. Madrid, Gráficas Ultra, 1947, p. 327. 
Pero es que los mecanismos diferentes obedecen a intenciones distintas. A Cervantes no le interesa tanto, en el Quijote y en este particular asunto, pillar en pecado cocheril a Sancho, como condenar indirectamente a los duques $o$, al menos, señalar a media voz ciertas paradojas insultantes para la vieja nobleza. Aunque tampoco excluya la posibilidad de introducir una instantánea de Teresa Corchuelo-Panza yendo en coche o un gracioso contraste implícito entre ella de tal guisa y su marido a lomos de un asno rucio rodado casi tan humano como él mismo. En El ingenioso hidalgo don Quijote pronuncia la frasecilla vulgar y porcina «andar a coche acá, cinchado» (II, 8) aplicada a la honra ${ }^{34}$, pero no la convierte en una alusión fácil al coche, como los otros autores de su siglo.

La comparación de nuestro pasaje con el citado de su entremés en El vizcaíno fingido o con el de El licenciado Vidriera puede, asimismo, ilustrar este contraste. En estas obras se entrega con más o menos denuedo a las bromas malévolas de moda, y mientras, por ejemplo, en la pieza de teatro menor, Brígida, dama de poco más o menos, se sentía morir tras leer la famosa premática de enero de 1611 que prohibía andar en coche a las de su profesión ${ }^{35}$, en el Quijote desaparece la nota de condena moral unida a la profesión de la dama entremesil. La buena o mala índole de los caracteres es relativa y se ha desvanecido ya la tendencia nativa del entremés a convertir a los seres humanos en tipos grotescos o moralizantes. La presentación de la sociedad hecha por las piezas entremesiles tendía a ser grotesca en extremo. En las de Cervantes, como pertenecientes a la etapa pre-quevedesca del género, esta característica se halla en estado embrionario, aunque se adivina la distancia estilística frente a la obra maestra cervantina. Los entremeses de otros autores, como el citado de Los coches de Quiñones de Benavente, arrojan un balance en todo semejante al de El vizcaíno. Quiñones presenta, por ejemplo, a una linda enamorada de un Don Vinoso ridículo pero armado de coche "con caballo y medio» ${ }^{36}$. La broma contemporánea de la longitud de los tiros ya nos habla del tipo de chiste por reducción al absurdo que dicta el género, mientras que la vinosidad del galán lo dice todo acerca de la grosera tipificación y del alejamiento de lo novelesco que imperan en el entremés. Por su parte, volviendo a Cervantes, Tomás Rodaja ataca los coches en un tono epigramático y con un arsenal de juegos léxicos próximos a los de Calderón, Vélez, Salas o Quevedo. Vidriera contesta a un

34 Rodríguez Marín explica en su edición citada del Quijote de 1922 (vol. V, p. 150) que, a pesar de la mala lectura de Clemencín, la frase alude a la llamada del ganado porcino "coche».

35 Ed. cit., p. $152 \mathrm{n}$.

36 Ed. cit., p. 73. 
pregonero que anuncia que sacan a azotar a una alcahueta con el chiste siguiente: «Si dijeras que sacaban a azotar a un alcagüete, entendiera que sacaban a azotar un coche» ${ }^{37}$.

El Quijote recurre, en cambio, al expediente menos retórico y más novelístico de las ambigüedades reveladoras. Las teorías nobiliarias cervantinas basadas en el mérito propio y en la propia virtud aparecen relativizadas, pues no vemos de ellas más que su reflejo en las acciones y en las palabras de un aldeano tonto-listo y de un loco iluminado. Con testigos tan poco firmes doctrinalmente, el sistema gana humanidad, cercanía y probabilidad. La sátira barroca va a tender, en cambio, en los años que siguen a 1600, a distanciar al narrador, al personaje y al lector de la realidad. La visión se deshumaniza al alzarse hasta las atalayas y los vuelos de diablos por el cielo de Madrid o al encumbrarse burlescamente hasta los tribunales y jueces cómicos. En una palabra: la sátira adopta una perspectiva aérea o de superioridad jerárquica unida siempre a un tono apocalíptico y moralizante. El Cervantes del Quijote, ajeno a tales ejercicios, nos brinda un ejemplo de literatura terrestre en el que la moralina es sustituida por una aguda insinuación moral y social de largo alcance.

Consecuentemente, el asunto cocheril es dejado también en manos de Sancho y Teresa, a los que contemplamos tan de cerca como en la vida misma. Ni se les reprenden sus pretensiones ni se les autoriza a cochizar. Más bien se da a entender a las calladas que la aldeana no es peor candidata a ruar coche que los nobles que gobiernan como verdaderos gerifaltes (o sea, halcones) y engañan a los inocentes. El coche de caballos se ha convertido, tocado por la fina ironía cervantina, en una máquina moral-social, en un vehículo estoico lanzado contra la muralla del casticismo y su obra maestra ha vuelto a renunciar al mero avatar retórico.

\section{HÉCTOR BRIOSO SANTOS}

37 Novelas ejemplares, edición de HARRY Sieber. Madrid, Cátedra, 1991, II, p. 60. Y la broma es corriente, por ejemplo, en Quevedo: cf. la Poesía varia compilada y editada por JAmEs O. Crosby. Madrid, Cátedra, 1992, p. 353. 